\title{
Relação entre dor e antecedentes de adoecimento físico ocupacional: um estudo entre músicos instrumentistas
}

\author{
Thaís Branquinho Oliveira Fragelli (UnB, Brasilia) \\ tbranquinho@unb.br \\ Isolda de Araújo Günther (UnB, Brasilia) \\ isolda@unb.br
}

\begin{abstract}
Resumo.Este artigo examina possíveis relações entre os sintomas de dor e os antecedentes físicos (carga física e ambiente físico de trabalho) e psicossociais (carga cognitiva, carga psíquica, organização do trabalho) de tais sintomas em um grupo de músicos instrumentistas. O trabalho constitui uma pesquisa exploratória envolvendo dados quantitativos e qualitativos e busca compreender aspectos relacionados aos fatores antecedentes do adoecimento muscular segundo a percepção dos músicos. A amostra foi composta por 46 músicos do estado de Goiás e do Distrito Federal, com idades entre 14 e 45 anos, que responderam a um questionário desenvolvido para este estudo. A análise quantitativa realizada por meio do coeficiente de correlação $\rho$ de Spearman indicou uma relação entre a dor e a carga física de trabalho percebida pelo respondente. Os resultados da análise qualitativa confirmaram esta relação entre percepção de dor e carga física. Os resultados são discutidos apontando a necessidade de disseminar a idéia de que o músico deve atentar para sinais de desarmonia do próprio corpo.

Palavras-chave: dor, músicos, lesões ocupacionais, antecedentes físicos, antecedentes psicossociais.
\end{abstract}

\section{Relationship between pain and antecedents of occupational illness: a study among musicians}

\begin{abstract}
This paper examines possible relationships between the presence of symptoms of pain and their physical antecedents (physical load and physical environment of work) and psychosocial antecedents (cognitive load, psychical load, work organization) of these symptoms in musicians. It constitutes an exploratory study involving quantitave and qualitative data that aim to understand aspects related to antecedents factors in the muscular infirmity according to musicians' perceptions. The sample was composed by 46 musicians from the State of Goiás and the Federal District in Brazil, aged 14 through 45, which answered a questionnaire developed for the study. The quantitative analysis, done with Spearman $\rho$ correlation, indicated a relationship between pain and physical work load perceived by the respondents. The qualitative analysis confirmed this relationship between perception of pain and physical load. The results point out to the necessity to disseminate the idea that musicians must pay attention to signs of disharmony in their own body.
\end{abstract}

Keywords: pain, musicians, occupational injuries, physical antecedents, psychosocial antecedents.

\begin{abstract}
1. Introdução
0 objetivo deste trabalho é verificar possiveis relações entre a presença de desconforto, sendo aqui caracterizado pela presença de dor, e os antecedentes físicos (carga física e ambiente físico de trabalho) e psicossociais (carga cognitiva, carga psíquica, organização do trabalho) de adoecimento músculo-esquelético entre músicos instrumentistas. Compreende-se por carga física a atividade muscular. 0 termo fator psicossocial refere-se a toda variável do ambiente ocupacional de natureza não física (PINHEIRO, TRÓCCOLI e PAZ, 2002) correspondendo, neste trabalho, às cargas cognitiva e psíquica. A carga cognitiva diz respeito à percepção, à atenção e à concentração e a carga psíquica é representada pelo grau de sofrimento vivenciado pelos indivíduos (CRUZ, 2004).
\end{abstract}

A Organização Mundial de Saúde (OMS) preconiza que as doenças relacionadas ao trabalho são consideradas multifatoriais, pois incluem fatores de ordem física, organizacional, psicossocial, individual e sociocultural (PINHEIRO, TRÓCCOLI e PAZ, 2002). No que tange a este aspecto, observa-se que, nas últimas décadas, houve maior número de pesquisas relacionadas aos riscos ambientais, individuais, sociais e ocupacionais relacionados ao aumento de queixas sobre desconforto músculo-esquelético na população trabalhadora (CRUZ, 2004).

Segundo BRITO, ORSO e GOMES (1992) as doenças ocupacionais, definidas inicialmente como doença dos digitadores, são atualmente também diagnosticadas 
entre músicos. Nesta perspectiva, a profissão de músico, por meio da relação entre potenciais fatores de risco de lesões e do fenômeno adoecer, apresenta uma predisposição para um descompasso nas condições de saúde e bem-estar, podendo ocasionar uma ruptura de tais condições. 0 fazer musical, dentro da análise de PETRUS E ECHTERNACHT (2004), compõe-se de um paradoxo em que de um lado procura-se a interpretação, a sincronia, a harmonia e a perfeição de sons e, de outro lado, este mesmo corpo pode desarmonizar-se quando ultrapassa seus limites fisiológicos.

A análise da literatura apontou que o sintoma de dor é freqüente na prática musical (TUBIANA, 1991; ZAZA, CHARLES e MUSZYNSKI, 1998, ANDRADE e FONSECA, 2000, COSTAe ABRAÃO, 2002). No Brasil, a literatura ainda contempla poucos estudos que relatam a freqüência com que ocorre tal sintoma ou que discutem suas causas e conseqüências (ANDRADE e FONSECA, 2000). As razões de tal lacuna podem ser decorrentes da falsa idéia de que a música se associa apenas ao lazer estando, portanto, raramente relacionada a uma atividade laboral.

Outra idéia muito propagada é a de que a excelência musical é conseguida por meio de uma dedicação que ultrapasse limites fisiológicos, que desconsidere, inclusive, as diferenças individuais, o chamado virtuosismo. Segundo PINTO (2001), o conceito de virtuosismo surgiu no século XIX sendo exemplificado nas figuras do violinista Niccolo Paganini (1782-1840) e do pianista Franz Liszt (18111886) que levaram a prática de seus instrumentos a perfeições jamais imaginadas.

A demanda física e psicológica a que o músico é submetido é relatada em vários estudos (COSTA, 2003; PETRUS e ECHTERNACHT, 2004; CINTRA e BARRENECHEA, 2004). Estes estudos sinalizam que para que o músico seja reconhecido como tal é necessário um treinamento com prática diária, repetição e interpretações diferenciadas a cada execução do mesmo trecho, com a finalidade de se obter uma memória cinestésica que resulte em uma performance segura (COSTA, 2003).

CINTRA E BARRENECHEA (2004) relatam que a demanda exigida pela tarefa exerce influência significativa sobre o aumento do nível de estresse repercutindo, consequentemente, sobre o comportamento. Assim, segundo tais autores, existe uma obsessão e um perfeccionismo para o cumprimento de um programa, além de dificuldades em reconhecer e lidar com os próprios limites, somada à competitividade do meio e às cobranças dos professores e/ou críticos. Há, no instrumentista, uma busca incansável por uma técnica aperfeiçoada, exigindo assim, longas horas de estudo chegando até a privação do convívio social, que podem aumentar o risco de lesão ocupacional (CINTRA $E$ BARRENECHEA, 2004; COSTA, 2003). Existe ainda um medo de errar e de transformar toda dedicação e estudo em frustração, o que causa ansiedade para apresentar-se perante um grande público ou até mesmo para amigos (CINTRA E BARRENECHEA, 2004).

De acordo com MOURA, FONTES E FUKUJIMA (2000), as atividades repetitivas diárias e rotineiras, necessárias para um bom desempenho técnico do músico, podem ser prejudiciais ao organismo, produzindo um efeito de tensão cumulativa nos tecidos, excedendo o limiar de tolerância fisiológica podendo produzir incapacidades. Os autores relatam que o limite psicológico associado às injúrias adquiridas, pode prejudicar ou até mesmo pôr fim, a uma carreira profissional.

\section{Método}

\subsection{Sujeitos}

A amostra foi composta por 46 músicos profissionais do estado de Goiás e do Distrito Federal. Dentre eles 38 são homens, 6 são mulheres e 2 não informaram. A idade variou entre 14 e 45 anos, perfazendo uma média de 26,3 anos $(d p=8,5)$. 0 tempo de prática do instrumento variou de 3 a 34 anos, perfazendo uma média de 13,5 anos ( $d p=$ 8,3). 0 tempo médio diário dedicado ao ensaio é de 3,0 horas $(\mathrm{dp}=1,6)$. Quanto ao instrumento executado, foram apontados os seguintes: clarineta, trombone, saxofone, bateria, trompete, piano, cavaquinho, violino, teclado, guitarra e violão.

\subsection{Procedimento}

A amostra foi do tipo não probabilística. Inicialmente, participantes potenciais foram contatados em um grupo de músicos do estado de Goiás e de uma universidade do Distrito Federal. Em seguida foram esclarecidos sobre os objetivos da pesquisa e os que mostraram interesse em fazer parte do estudo foram convidados a colaborar voluntariamente e a disponibilizar tempo para aplicação do instrumento. 0 questionário foi auto-aplicado, em situação de grupo. Foi-Ihes garantido que suas respostas seriam tratadas com total sigilo, sendo apresentados apenas resultados globais, sem qualquer indicação que pudesse levar à identificação especifica de um ou mais participantes.

\subsection{Instrumento de pesquisa}

0 instrumento de pesquisa utilizado neste trabalho foi um questionário idealizado e desenvolvido para 0 estudo em questão. ${ }^{1}$ É composto por 78 questões entre perguntas abertas e fechadas, tendo duas partes distintas: a caracterização dos sujeitos e os dados relacionados aos fatores físicos (carga física e do ambiente físico de trabalho) e psicossociais (carga psíquica, cognitiva e organização do trabalho).

Com relação à carga física foram inseridos itens relacionados à percepção de fadiga, desconforto em relação às posturas e movimentos exigidos, como por exemplo, "Os movimentos repetitivos da minha atividade me incomodam". A respeito da carga cognitiva, os itens abrangeram a exigência de concentração e dedicação ("Tenho que ficar atento aos 
detalhes da tarefa"). Para investigar a carga psíquica foram utilizados itens que se relacionavam à pressão para o cumprimento da tarefa, satisfação com o trabalho, relacionamento interpessoal no trabalho ("Conflito entre o que eu consigo realizar e o que é exigido de mim"). Para incorporar dados ligados ao ambiente físico de ensaio foram relacionados itens que se referiam à iluminação, à acústica, ao posto de trabalho, entre outros ("A iluminação permite o uso da visão de forma confortável"). E por fim, a organização do trabalho se referiu à satisfação na administração das atividades, aos horários de trabalho, à obrigação de levar trabalho para casa entre outros ("0 cronograma de trabalho é irregular").

$\mathrm{Na}$ fase de desenvolvimento do questionário deu-se especial importância à relação entre os objetivos do estudo e os itens propostos, em consonância com a revisão da literatura relacionada ao tema. Atentou-se, sobremaneira, para a clareza e adequação lingüística do item.

Além dos dados demográficos e das informações relacionadas ao tipo de instrumento musical, tempo de prática, freqüência e duração dos ensaios, foram levantados dados referentes à presença/ausência de dor, aos fatores físicos e psicossociais do trabalho abrangendo as dimensões ligadas às cargas física, cognitiva, psíquica, à organização e ao ambiente físico de trabalho.

Objetivando verificar a compreensão do questionário e proceder a sua validação semântica, realizou-se uma aplicação do mesmo em um grupo de 5 profissionais não músicos. Como resultado desta aplicação alguns itens do instrumento foram substituídos ou alterados.

Quando da elaboração do instrumento optou-se, em um primeiro momento por utilizar respostas dicotômicas (sim/ não) por acreditar que facilitaria a sua compreensão e por julgar que poderia reduzir a subjetividade. Em uma segunda etapa foram incluídas perguntas abertas a fim de obter dados qualitativos. Para a avaliação quantitativa dos itens presentes nas dimensões foi atribuído o valor 2 para respostas de conotação positiva, e valor 1 para as de conotação negativa. Os itens foram dispostos aleatoriamente, intercalando questões de conotação positiva com negativa.

\section{Resultados}

Esta pesquisa teve como propósito determinar possiveis relações entre a presença de dor e antecedentes físicos e psicossociais de adoecimento músculo-esquelético entre músicos, por meio da investigação das seguintes dimensões: carga física, carga cognitiva, carga psíquica, organização do trabalho e ambiente físico de trabalho.

\subsection{A análise quantitativa: 0 que dizem os números}

\subsubsection{A dor}

Com relação à presença de dor, 27 respondentes relataram ter atualmente tal desconforto, sendo os locais mais citados as mãos, os braços, os ombros e coluna cervical e lombar.

\subsubsection{A Carga física}

No que diz respeito à carga física observou-se que os itens referentes à postura estática (permaneço muito tempo na mesma posição) e à sensação de fadiga física (sinto cansaço físico no final do expediente) foram os que tiveram freqüências mais elevadas. Trinta e sete sujeitos relataram respostas positivas à questão e trinta e um informaram ter fadiga ao final do expediente. Dezenove participantes relataram incômodo com as posturas exigidas na execução do trabalho

\subsubsection{A Carga psíquica}

Com relação aos itens referentes à carga psíquica, 23 respondentes percebiam conflito entre o que conseguiam realizar e o que lhes era exigido. Trinta e oito entrevistados relataram ser o salário incompatível com as exigências do trabalho, e 39 sujeitos relataram ser a profissão pouco valorizada.

\subsubsection{A Carga cognitiva}

Com relação a ter que se manter concentrado durante a tarefa, 44 dos sujeitos responderam afirmativamente. Dentre os respondentes 39 relataram se sentirem obrigados a se dedicar o máximo possível, 45 sujeitos relatam necessidade de ficarem atentos aos detalhes da tarefa e 34 sujeitos indicaram sentir-se obrigados a não cometerem erros.

\subsubsection{A Organização do trabalho}

$\mathrm{Na}$ análise dos itens referentes à organização do trabalho, 32 participantes relataram fazer a mesma tarefa todos os dias. Cerca de 40 sujeitos referiram não poder escolher 0 período de férias e 31 relataram ter que levar trabalho para casa. Com relação aos prazos para execução das tarefas, 28 respondentes relataram ter prazos muito curtos.

\subsubsection{Ambiente físico de trabalho}

Com relação ao conforto do mobiliário utilizado para 0 trabalho, 20 participantes informaram sentir desconforto. Vinte e quatro respondentes relataram irritação com a interferência de ruido/som constante e 26 indicaram que a acústica do ambiente dificulta o trabalho.

\subsubsection{Relação entre presença de dor e antecedentes físicos e psicossociais}

Comoobjetivo deverificararelaçãoentreapresença de dor e os antecedentes físicos e psicossociais envolvidos no adoecimento músculo-esquelético presentes na atividade do músico, calculou-se a correlação $\rho$ de Spearman apresentada na Tabela 1. Os resultados indicaram uma correlação positiva estatisticamente significativa entre dor e carga física $(\rho=0,545 ; p=0,000)$, bem como entre dor e carga cognitiva $(\rho=0,257 ; p=0,042)$, indicando que quanto mais carga física ou carga psíquica, mais dor. Além disso, foi observada uma correlação positiva entre carga física e carga psíquica $(\rho=0,287 ; p=0,026)$ e carga psíquica e organização do trabalho $(\rho=0,301 ; p=0,021)$. 


\subsection{Análise Qualitativa: 0 que dizem os indivíduos}

A análise qualitativa teve como base as perguntas abertas. Considerando a presença de dor, foi perguntado ao músico qual o significado que ele atribuía ao sintoma "dor". Observou-se que os indivíduos relacionavam dor à carga percebida de trabalho, seja ela física, psíquica ou cognitiva. Assim, ao contrário do efeito de bem-estar que a música proporciona ao ouvinte, a dor pode ser, para quem toca, o resultado daquilo que soa como belas melodias e harmonias para a platéia, que se traduz em "incomodo" e "sofrimento" segundo o relato dos músicos.

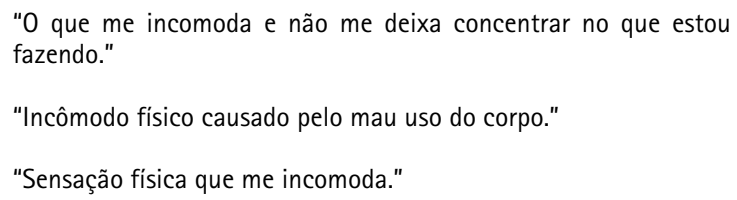

Tais relatos verbais demonstram que a dor é percebida como causa de desconforto ou pelos efeitos que proporciona. Outros relatos incluem, ainda, queixas localizadas em determinado local como, por exemplo, "um incômodo na mão".

A relação percebida na análise dos dados quantitativos entre a carga física e a dor também pôde ser confirmada nos relatos dos sujeitos quando indagados quanto ao que avaliam como capaz de piorar a sua dor. Elementos relacionados a fatores como manter uma mesma posição por muito tempo, postura inadequada, uso de força e até falta de medidas preventivas foram relacionadas, conforme exemplificado nos depoimentos abaixo:

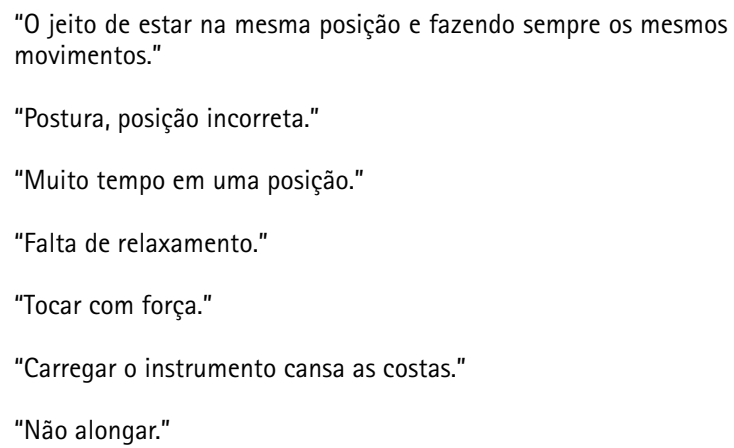

\subsection{A interação com os sujeitos}

Os músicos se mostraram bastante receptivos quanto à pesquisa, prontos a colaborar, manifestando interesse e colocando-se a disposição para trabalhos futuros. Apenas 01 (um) sujeito não manifestou interesse em responder ao questionário, relatando falta de tempo.

Houve também relatos espontâneos de sintomas e queixas, bem como da necessidade de equipes médicas especializadas para atender aos profissionais da performance musical.

Finalmente, foi perguntado como o sujeito se sentiu respondendo ao questionário. Os relatos apontaram para o sentimento de estar sendo valorizado e para a perspectiva de mudança na realidade profissional.

"Senti muito feliz em saber que pessoas se preocupam com 0 músico, seu bem-estar, porque as pessoas acham bonito, mas não valorizam a pessoa do músico."

\section{Tabela 1: Correlações entre as variáveis}

\begin{tabular}{|l|c|c|c|c|c|}
\hline Variável & Dor & Carga física & Carga cognitiva & Carga psíquica & Ambiente físico \\
\hline Carga física & 0,545 & & & & \\
$\mathbf{p}$ & 0,000 & & & & \\
\hline Carga cognitiva & 0,257 & $-0,009$ & & & \\
$\mathbf{p}$ & 0,042 & 0,476 & & & \\
\hline Carga psíquica & 0,231 & 0,287 & 0,239 & & \\
$\mathbf{p}$ & 0,061 & 0,026 & 0,055 & & \\
\hline Ambiente físico & 0,086 & 0,138 & 0,017 & 0,157 & \\
$\mathbf{p}$ & 0,286 & 0,180 & 0,456 & 0,148 & \\
\hline Organização do trabalho & 0,030 & 0,231 & 0,033 & 0,301 & 0,203 \\
$\mathbf{p}$ & 0,421 & 0,062 & 0,415 & 0,021 & 0,089 \\
\hline
\end{tabular}




\section{Discussão}

Observou-se, no presente estudo, que 58,7\% dos participantes relataram a presença de dor. Este resultado confirma dados da literatura que apontam a incidência de 40 a 70\% de dor entre estes profissionais (TUBIANA, 1991; ZAZA, CHARLES e MUSZYNSKI, 1998; ANDRADE e FONSECA, 2000; COSTA e ABRAHÃO, 2002).

A análise entre a variável dor e os antecedentes físicos e psicossociais de adoecimento físico no trabalho indicou uma correlação positiva estatisticamente significativa entre carga física e dor, carga cognitiva e dor. Assim, indivíduos que relataram sentir dor indicaram maior carga física do que aqueles que não relataram dor. Foi demonstrada também, pelos relatos dos sujeitos, uma relação entre a piora da dor, quando em presença de algum fator que exigisse maior demanda física como, por exemplo, uma postura inadequada, manter-se em uma mesma posição ou carregar o instrumento musical. Uma correlação entre carga física e carga psíquica também foi encontrada, sugerindo que um esforço físico maior durante a atividade acarretaria maior sensação de dor, implicando em um aumento da percepção do sofrimento psíquico. A organização do trabalho também demonstrou uma correlação estatisticamente significativa com a carga psíquica. Logo, o cronograma das atividades, o horário de trabalho, os prazos, a autonomia são exemplos de fatores que interferem na satisfação psicológica do trabalho do músico.

As demais variáveis não obtiveram resultados significativos nas análises efetuadas, apesar das altas freqüências em alguns itens relacionados a estas dimensões.
A carga física foi, portanto, a dimensão que obteve 0 resultado mais significativo. Os itens relativos a esta dimensão e referentes à percepção de desconforto nas posturas utilizadas durante a atividade ("As posturas exigidas na execução do meu trabalho me incomodam"), à sensação de fadiga ("Os movimentos repetitivos da minha atividade me incomodam") e à postura estática ("Permaneço muito tempo na mesma posição") foram os que obtiveram maior representatividade no presente estudo, sendo confirmados, ademais, por meio do relato dos respondentes.

Não obstante as limitações por se tratar de uma amostra não probabilística, e da cautela quanto ao poder de generalização dos resultados deste estudo é possivel apontar uma relação entre a demanda física da profissão e a incidência de dor entre músicos. Tendo em vista que fatores relacionados à carga física no trabalho destes profissionais desempenham um papel determinante no surgimento da dor, conforme é demonstrado pela literatura, por estudos anteriores (COSTA, 2003; PEDERIVA, 2005) e corroborados por este estudo, é importante difundir a idéia de que não só a música deve ser ouvida e harmonizada, mas também os sinais de descompasso do próprio corpo.

Nesta perspectiva e refletindo sobre as implicações destes resultados, bem como na conveniência de disseminar estes conhecimentos entre aqueles que podem aplicá-los, contribuindo para uma melhoria das condições de saúde entre a pessoa que toca e o profissional, é que chamamos atenção para a necessidade de novos estudos. Diminuir a distância entre a pesquisa e sua aplicação é um desafio e uma meta que devem ser buscados em pesquisas futuras. 


\section{Referências}

ANDRADE, E.Q.; FONSECA, J.G.M. Artista-atleta: reflexões sobre a utilização do corpo na performance dos instrumentos de cordas. Per Musi, Belo Horizonte, v.2, p.118-128, 2000.

BRITO, A C.; ORSO, M. B; GOMES, E. Lesões por esforços repetitivos e outros acometimentos reumáticos em

músicos profissionais. Revista Brasileira de Reumatologia, São Paulo, v.32, n.2, p.79-83, 1992.

CINTRA, S.; BARRENECHEA, L. A lesão por esforço repetitivo no contexto pianistico. In: SEMINÁRIO NACIONAL DE PESQUISA EM MÚSICA, IV, 2004, Goiânia, GO. Anais do IV Seminário Nacional de Pesquisa em Música, Goiânia, 2004.

COSTA, C. Quando tocar dói: análise ergonômica do trabalho de violistas de orquestra. Brasilia, 2003. Dissertação (Mestrado em Psicologia), Instituto de Psicologia, Universidade de Brasília, 2003.

COSTA, C.P.; ABRAHÃO, J. I. Músico: profissão de risco? In: CONGRESSO LATINO-AMERICANO, CONGRESSO BRASILEIRO DE ERGONOMIA, VII, XII 2002, Recife, PE. Anais do VII Congresso Latino-Americano e XII Congresso Brasileiro de Ergonomia, 2002.

CRUZ, R.M. Distúrbios musculoesqueléticos, processos de trabalho, e cultura organizacional. In: TAMAYO, A. \& COLS (Org), Cultura e Saúde nas Organizações Porto Alegre: Artmed, 2004. p.231- 252.

MOURA, R.C.R.; FONTES, S.V.; FUKUJIMA, M.M. Doenças Ocupacionais em Músicos: uma Abordagem Fisioterapêutica. Rev. Neurociências, São Paulo, v.8, n.3, p.103-107, 2000.

PEDERIVA, P.L.M. 0 corpo no processo ensino-aprendizagem de instrumentos musicais: percepção de professores. Brasilia, 2005. Dissertação (Mestrado em Educação), Faculdade de Educação, Universidade Católica de Brasília, 2005.

PETRUS, A.M.F.; ECHTERNACHT, E.H.O. Dois Violinistas e uma Orquestra: Diversidade Operatória e Desgaste MúsculoEsquelético. Revista Brasileira de Saúde Ocupacional, São Paulo, v.29, n. 109, p.31-36, 2004.

PINHEIRO, F.A.;TRÓCCOLI, B.T. e PAZ, M.G.T. Aspetos Psicossociais dos Distúrbios Osteomusculares (DORT/LER) Relacionados ao Trabalho. In: MENDES, A.M.; BORGES, L.O. ; FERREIRA. M.C. (Org.), Trabalho em Transição Saúde em Risco, Brasília: UnB/FINATEC, p.65- 85, 2002.

PINTO, T.0. Som e música. Questões de uma antropologia sonora. Rev. Antropo, São Paulo, v.44, n.1, p.222-286, 2001.

TUBIANA R. The surgeon and the hand of the musician. The hand and Science today, s/v, p.44-55, 1991.

ZAZA, C.; CHARLES, C.; MUSZYNSKI, A. The Meaning of Playing-Related Musculoskeletal Disorders to Classical Musicians. Social Science and Medicine, v.47, n.12, p.2013-2023, 1998.

Thaís Branquinho Oliveira Fragelli é Fisioterapeuta pela Universidade Estadual de Goiás (UEG) e especialista em Fisioterapia Neurofuncional pela Universidade de Brasilia (UnB) e mestre em Psicologia Social do Trabalho e das Organizações pela UnB. Foi docente no Centro de Ensino Profissional Escola de Música de Brasília ministrando a disciplina Proteção ao Trabalho/Prevenção a LER/DORT. Realizou palestras e cursos relacionados à prevenção de lesões em músicos.

Isolda de Araújo Günther possui graduação em Psicologia pela Universidade Católica de Pernambuco, especialização em Psicologia Clínica pela Universidade Federal de Pernambuco, mestrado em Psicologia Social pela Universidade Federal da Paraiba, doutorado em Psicologia do Desenvolvimento pela Michigan State University, pós-doutorado pela City University of New York e pela Carl von Ossietzky Universität Oldenburg. Atualmente é pesquisadora associada sênior no Instituto de Psicologia da UnB.

\section{Notas}

${ }^{1} 0$ instrumento de pesquisa será publicado posteriormente. 